\title{
Transforming Through Reflection: Use of Student-Led Reflections in the Development of Intercultural Competence during a Short- Term International Immersion Experience
}

Diane Ceo-DiFrancesco

Xavier University, ceo-difr@xavier.edu

Leah S. Dunn

Xavier University - Cincinnati, dunnl3@xavier.edu

Nathalie Solorio

Xavier University, Cincinnati, $\mathrm{OH}$, solorion@xavier.edu

Follow this and additional works at: https://nsuworks.nova.edu/ijahsp

Part of the Occupational Therapy Commons

This Manuscript has supplementary content. View the full record on NSUWorks here: https://nsuworks.nova.edu/ijahsp/vol18/iss2/8

\section{Recommended Citation}

Ceo-DiFrancesco D, Dunn LS, Solorio N. Transforming Through Reflection: Use of Student-Led Reflections in the Development of Intercultural Competence during a Short-Term International Immersion Experience. The Internet Journal of Allied Health Sciences and Practice. 2020 Jan 01;18(2), Article 8.

This Manuscript is brought to you for free and open access by the College of Health Care Sciences at NSUWorks. It has been accepted for inclusion in Internet Journal of Allied Health Sciences and Practice by an authorized editor of NSUWorks. For more information, please contact nsuworks@nova.edu. 


\title{
Transforming Through Reflection: Use of Student-Led Reflections in the Development of Intercultural Competence during a Short-Term International Immersion Experience
}

\begin{abstract}
ABSTRACT

Purpose: Curricular integration designed to include cultural competence standards for health care professionals is paramount to preparing students to meet the needs of a growing diverse population in the U.S. The purpose of this research is to examine the cultural competency development of occupational therapy students, and to report on their reflections and perspectives during a two-week immersive and service-learning experience in Guatemala. Methods: As intercultural competence is a highly personal trait, the study used a descriptive qualitative research design gaining participants' perspectives of the short-term international immersion experience through student-led reflective focus groups, using an open discussion format, during the immersion experience. Results: Data analysis yielded three themes: Do, Experience, Understand; Change Factor; and Future Action that represent the student perspective in a cultural immersion experience. The first theme: Do, Experience, Understand encompassed participants' discussion of how fully engaging in a culture different than their own was necessary to understand differences and commonalities. The second theme: Change Factor included expressions of dissonance in level of physical, emotional, and mental comfort that prompted a transformation within the student. The final theme: Future Action, described a tangible outcome from the immersion experience. By engaging with a different culture, participants experienced a transformation, leading to sharing of their desire to continue their advocacy efforts on behalf of others. Conclusion: Reflection became a key element in the transformative nature of the learning experience. It became obvious that a safe environment in which to share dreams, doubts, cultural missteps and successful moments was necessary for coping with feelings of dissonance. The safe sharing environment added to the cohesiveness of the group, lowered anxiety and provided opportunities for learning. Participants' verbalized descriptions of transformative learning necessary in the development of intercultural competency during an international cultural immersion experience. By participating in a cultural immersion experience integrated into their curricular program, students began to articulate cultural competencies required to consider multiples lenses, perspectives and backgrounds of their future clients.
\end{abstract}

\section{Author Bio(s)}

Diane Ceo-DiFrancesco, $\mathrm{PhD}$, is an associate professor of Spanish and Faculty Director of the Eigel Center for Community-Engaged Learning at Xavier University in Cincinnati, Ohio. She has designed and implemented immersion experiences for students and faculty in Guatemala, Nicaragua, Peru, Mexico, Spain, and Costa Rica.

Leah S. Dunn, EdD, OTR/L, is an assistant professor in the Department of Occupational Therapy at Xavier University in Cincinnati, Ohio. She has participated in international service learning experiences with her students for five years and continues to assist with the planning and evaluation of those experiences.

Nathalie Solorio is a research assistant at Xavier University in Cincinnati, $\mathrm{OH}$ and candidate for a K-12 Spanish teaching license in the state of Ohio. She completes majors in Spanish and minors in Education and Peace and Justice Studies and is a Community Engaged Fellow.

Acknowledgements

ACKNOWLEDGEMENTS The authors would like to thank the students' authentic participation in the study.

This manuscript is available in Internet Journal of Allied Health Sciences and Practice: https://nsuworks.nova.edu/ijahsp/vol18/iss2/8 


\title{
IITAHSP \\ The Internet Joumnal of Allied Health Sciences and Practice \\ Dedicated to allied health professional practice and education
}

Vol. 18 No. 2 ISSN 1540-580X

\section{Transforming Through Reflection: Use of Student-Led Reflections in the Development of Intercultural Competence During a Short-Term International Immersion Experience}

\author{
Diane Ceo-DiFrancesco \\ Leah S. Dunn \\ Nathalie Solorio \\ Xavier University \\ United States
}

\begin{abstract}
Purpose: Curricular integration designed to include cultural competence standards for health care professionals is paramount to preparing students to meet the needs of a growing diverse population in the U.S. The purpose of this research is to examine the cultural competency development of occupational therapy students, and to report on their reflections and perspectives during a two-week immersive and service-learning experience in Guatemala. Methods: As intercultural competence is a highly personal trait, the study used a descriptive qualitative research design gaining participants' perspectives of the short-term international immersion experience through student-led reflective focus groups, using an open discussion format, during the immersion experience. Results: Data analysis yielded three themes: Do, Experience, Understand; Change Factor; and Future Action that represent the student perspective in a cultural immersion experience. The first theme: Do, Experience, Understand encompassed participants' discussion of how fully engaging in a culture different than their own was necessary to understand differences and commonalities. The second theme: Change Factor included expressions of dissonance in level of physical, emotional, and mental comfort that prompted a transformation within the student. The final theme: Future Action, described a tangible outcome from the immersion experience. By engaging with a different culture, participants experienced a transformation, leading to sharing of their desire to continue their advocacy efforts on behalf of others. Conclusion: Reflection became a key element in the transformative nature of the learning experience. It became obvious that a safe environment in which to share dreams, doubts, cultural missteps and successful moments was necessary for coping with feelings of dissonance. The safe sharing environment added to the cohesiveness of the group, lowered anxiety and provided opportunities for learning. Participants' verbalized descriptions of transformative learning necessary in the development of intercultural competency during an international cultural immersion experience. By participating in a cultural immersion experience integrated into their curricular program, students began to articulate cultural competencies required to consider multiples lenses, perspectives and backgrounds of their future clients.
\end{abstract}

Keywords: short term immersion, immersive learning, reflection, preparation of occupational therapists, intercultural competence 


\section{INTRODUCTION}

The profession of occupational therapy lacks diversity in gender and ethnic background in the United States. ${ }^{1}$ Yet, cultural diversity continues to increase across the globe through technology, mobility and migration. The current standards and newly adopted standards which will be in effect in 2020, developed by the Accreditation Council for Occupational Therapy Education (ACOTE ${ }^{\circledR}$ ), require the consideration of client cultural factors during the occupational therapy process. ${ }^{2,3}$ The dominant cultural background of occupational therapy practitioners and current students of occupational therapy presents a potential imbalance with their clients, and without sufficient background and training in intercultural competency, professionals may practice from a position of power, imposing perspectives from the dominant culture. Curricular integration designed to include cultural competence standards for health care professionals is paramount to preparing students to meet the needs of a growing diverse population in the U.S. ${ }^{2,3}$

Although occupational therapy preparation programs are required to prepare students for their work with diverse populations and to address intercultural competence, academic coursework does not adequately prepare students to work with a diverse client base.., 5 In contrast, educational programs can address this preparation shortcoming through a variety of programs, such as study abroad, service-learning or immersion programs which can involve a fieldwork component. In fact, short-term international immersion programs are increasingly becoming a means of integrating the development of intercultural competencies in preparation programs for future health care professionals. $6,7,8$ In addition, international service-learning opportunities are cited as integral to pre-professional programs, particularly towards addressing occupational justice, yet efforts to create sustainable programs are often in initial stages of development. ${ }^{9}$ Existing research describes an immediate effect of participating in international service-learning programs on gains in knowledge related to intercultural competence, but does not describe the transformational process. Cultural knowledge gained does not guarantee growth in intercultural competence, because without critically reflecting on cultural perspectives distinct from one's own world lens, transformative learning cannot fully take place. ${ }^{10}$

In order to prepare students to become client-centered practitioners, research is needed to address how reflection promotes transformational learning during an international immersive service-learning experience. Given this need, the purpose of this research is to examine the cultural competency development of occupational therapy students, and to report on their reflections and perspectives during a two-week immersive and service-learning experience in Guatemala. This article explores the perceptions of undergraduate occupational therapy students during a cultural and language curricular international immersion experience, and describes their increasing cultural awareness towards developing intercultural competence in real time.

\section{REVIEW OF LITERATURE Intercultural Competence}

Researchers have studied the concept of intercultural competence for over five decades, yet a consensus on its definition has not been reached, in part because terminology differs based on the discipline. ${ }^{11,12} \mathrm{~A}$ short list of terms includes global competence, cultural intelligence, cross-cultural awareness, intercultural sensitivity, cultural competence and cultural humility. ${ }^{13}$ For the purposes of this research, the term intercultural competence will be used.

Culturally competent healthcare practice is a holistic view of the client, considering their cultural background during the provision of services. Black and Wells encourage the application of the knowledge of culture, socioeconomic background, attitudes and perspectives related to health care and behavioral patterns of a specific cultural group in order to create effective intervention plans. ${ }^{14}$ Muñoz conceptualizes a process model of "culturally responsive caring," which involves the interaction of cultural knowledge, awareness, skills, engagement with diverse others, and exploration of multiculturalism. ${ }^{15}$ However, cultural competent healthcare practice is an ongoing process throughout one's career as a practitioner. This process begins with understanding one's own cultural influences and the impact of the client's culture on the services provided.

A number of theories and models for describing intercultural competence have been developed, each featuring a particular aspect of the process. Models of intercultural competence in nursing and other allied health professions share commonalities, such as having an awareness for intercultural competence, seeking knowledge, developing skills, and engaging in interculturally-sound client interactions. ${ }^{16,17,18,19}$ Grady, Brungardt, and Doll emphasize the need for curricular approaches in occupational therapy education that focus on cultural awareness and sensitivity. ${ }^{20}$ The process of developing intercultural competence requires reflection on one's own cultural practices and perspectives, personal beliefs and biases as a first step toward deeper growth related to the cognitive, behavioral and emotional components of intercultural competence. ${ }^{20}$ To create consensus among a variety of theoretical frameworks of intercultural competence, Deardorff utilized the Delphi technique to develop an intercultural competence model. ${ }^{11}$ This model focuses on internal and external outcomes that result from the ongoing development of attitudes, knowledge and skills leading to intercultural competence. Key to the Deardorff circular model are the roles of critical thinking, reflection, and attitudes that affect the ongoing developmental process. According to Deardorff, experts agree on one aspect of intercultural competence, that of seeing the world through differing lenses and from different perspectives. ${ }^{11}$ 


\section{Reflection}

Educational theorists have identified reflection as a vital component of experiential learning, allowing students to develop meaning based on reflections of experiences. ${ }^{21,22}$ Mezirow focuses on significant learning experiences of adult learners, citing the key role of critical reflection in the reassessment of students' perceptions, leading to transformative learning. ${ }^{10}$ Furthermore, transformative learning occurs when students are exposed to alternative points of view. As they critically examine alternative ways of viewing a particular issue or topic, they begin to question their own values, beliefs, and assumptions, which can lead to a shift in the way they view the world and their place in it.23 Transformative learning can be prompted through pedagogical strategies or learning activities that provide opportunities for students to examine new ways of thinking and perceiving the world. It can also be prompted through provocative and challenging questions, critical reflection, and a supportive and encouraging learning environment. ${ }^{23}$ The role of context has been cited as significant in relation to critical reflection, and the relationships that learners have with each other play a role in influencing how and what they reflect. ${ }^{24}$

Savicki and Price recognized the role of reflection in immersion experiences, particularly international ones. ${ }^{25}$ Paige listed reflection as a best practice related to study abroad programs. ${ }^{26}$ Reflection provides the needed support to the students, thus avoiding excessive dissonance. Without this support, the uncomfortable feelings students experience can lead to strong dissonance and result in reinforcement of negative stereotypes. Implementation of reflection sessions should include both emotional and cognitive aspects which can be manipulated by context, prompts, and ultimately the types of experiences that educators provide for the learners. ${ }^{25}$

\section{International Experiences}

International interactions are likely to promote an increased desire to learn about one's self and others, exploring difficult topics of privilege and power. ${ }^{27}$ Darawshe and Chard proposed a model of cultural awareness, identifying the first step as reflection on differences, whether between therapist and client, or as a therapist working in a different culture than one's own. ${ }^{28}$ Students have multiple opportunities for international interactions, such as study abroad, service-learning, immersion, and fieldwork experiences. Study abroad experiences are associated with course credit and may be short-term or semester long. Students engaged in international experiences ranging from 1 week to 4 months reported a greater knowledge of themselves, awareness of a new culture, and having a greater sense of how to give back to the community upon return to their own country. ${ }^{29}$

International experiences promote the development of the attitudes and skills associated with intercultural competence, allowing students to engage in cultures distinct from their own. These experiences can offer students fully immersive interactions in another culture, usually while living with a local host family. Mu, Coppard, Bracciano, Doll, and Matthews explored two international servicelearning experiences with OT student, and found that the international experience led to the development of empathy and the ability to improvise in clinical settings. ${ }^{27}$ Another affective result of international experience included reports of students' anxiety and a greater sense of vigilance due to being an outsider when immersed in a culture other than their own, but students recognized the connections made with the local people. ${ }^{7}$ The most powerful finding, according to Ekelman, Bello-Haas, Bazyk, and Bazyk, was the alteration of students' worldviews once they returned home. ${ }^{7}$ Furthermore, international fieldwork experiences led to an increase in openness to working with multicultural clients in both practitioners and students, according to Crowe, Sanchez, Weber, and Murtagh. ${ }^{6}$ Fieldwork students in South Africa working in cultures other than their own found a new awareness of culture and recognized the impact of culture on interactions with clients. Students reported that looking beyond their personal cultural values was necessary to become a truly client-centered practitioner. ${ }^{30}$ Additionally, Simonelis, Njelesani, Novak, Kusma, and Cameron interviewed 14 occupational therapy students after an international fieldwork experience and found that they developed skills in collaborative learning, cultural negotiation, and independent thinking. ${ }^{31}$ These studies highlight the importance of an immersion experience in the development of intercultural competency in occupational therapy students.

Preparing occupational therapy students for work with diverse populations requires academic programing that takes students out of their comfort zones, immersing them in new contexts and exposing them to new perspectives. Models of intercultural competency share a commonality regarding the need for awareness of the existence of others and other ways of thinking, doing and being. International immersion programs can meet the preparation gap if intentionally planned to provide opportunities for ongoing intercultural competency development and transformative learning. Critical reflection supports learners throughout the learning experience, prompting them to examine and question existing values, perspectives and norms based on new experiences. Due to the important role of critical reflection, capturing learners' ongoing reflections throughout an immersion experience can shed insights into the transformative learning process. 


\section{METHODS AND PROCEDURES \\ Research Design}

As intercultural competence is a highly personal trait, this study used a descriptive qualitative research design, gaining participants' perspectives of the short-term international immersion experience through student-led reflective focus groups, using an open discussion format. ${ }^{32}$ Focus groups were audiotaped and transcribed. As a qualitative descriptive study, data collection occurred in a natural state, allowing description of the context in detail.

\section{Participants}

Participants in a qualitative descriptive study must have experience with the identified phenomenon and be willing to tell their stories. ${ }^{33}$ This study utilized purposive, convenience sampling. The participants $(\mathrm{N}=15 ; 100 \%$ female), participated in an international immersive service-learning program to Guatemala. Fifteen (15) out of 16 participants (enrolled students) gave consent for data analysis. Data was redacted for the student who declined consent. Participants were undergraduate occupational therapy students entering their fourth year of studies, all of whom are of Caucasian, of white descent, with an age range of 20-22 years. Five of the 15 students had prior international study abroad experience (see Table 1).

Table 1: Prior International Study Abroad Experience of Five Subjects

\begin{tabular}{|l|l|l|l|}
\hline Participant & Length of program & location & Type of program \\
\hline P5 & semester & Nicaragua & Service-learning \\
\hline P4 & 5 weeks & Italy & Study abroad \\
\hline P10 & 1 week & Nicaragua & Alternative break \\
\hline P13 & 4 weeks & Greece & Study Abroad \\
\hline P2 & semester & Italy & Study Abroad \\
\hline
\end{tabular}

For many of the participants, this program was the first time they had traveled outside the United States. For others, international travel had not been tied to an academic experience.

\section{Description of the Program}

Recognizing the need to prepare students to work with diverse populations, the occupational therapy department at a Midwestern Jesuit university instituted a service-learning program in Guatemala. Guatemala was chosen because the Hispanic/Latino population has been cited as the largest growing population in the U.S., estimated to reach $28 \%$ of the total U.S. population in $2060.3^{34}$

The program aligns with the mission of the Department of Occupational Therapy, which integrates the Jesuit mission by focusing on the education of the whole person and by preparing students to become client-centered practitioners. The first international service-learning program was offered in the summer of 2008, involving 12 therapists and 12 students. This program has continued each year since then, involving both practitioners and students in a train-the-trainer service-learning model. The purpose of the weeklong program is to examine the concepts of occupational justice theory and its connection to international contexts, to promote civic engagement through authentic learning experiences, and to promote an understanding of the role of culture as it pertains to occupations and quality of life. Aspects of occupational justice theory continue to evolve. The international service-learning program based its course objectives on Townsend's call for the occupational therapy profession to promote social justice by enabling occupation, highlighting an individual's right to engage in meaningful activities to meet basic needs and enhance their potential. ${ }^{35}$

To attend the program in Guatemala, participating students must enroll in two courses, Spanish 258 Language and Culture in Guatemala and HOCS 405 Occupational Justice II. The Spanish course includes an intensive one-week of language and cultural study prior to departure, and a one-week immersion in Guatemala. Students complete required course assignments for HOCS 405 following the service-learning component that takes place during the second week in Guatemala. The program's immersion and service-learning component includes a total of 15 days.

The Spanish course is specifically designed to prepare students linguistically for the interactions that they will encounter in clinical settings in Guatemala, and offers them cultural and historical background and social context for their international service-learning experience. The second week of the course is an immersion experience in Guatemala, involving host family stays and hands-on experiences that provide students with many opportunities to engage in Spanish with Guatemalans from a variety of backgrounds. Students explore provocative social justice issues through experiential learning activities. These include testimonials from survivors of Guatemala's 36-year civil war, interactions with children and teachers at an underfunded school for special needs children, and 
engagement with residents at a home for abandoned elderly women. Students also participate in a dialogue with the creator of a non-profit organization for returning migrants and in a market simulation activity to experience the cost of supporting a family of four on an average wage.

The service-learning program involves occupational therapy for children and adults with disabilities in children's homes, clinics and community health stations through a train-the-trainer model. Students are paired with U.S. volunteer practitioners and provide a supportive role by taking notes and photos and engaging with children in therapy settings. In addition to interacting with children and adults with disabilities, students communicate with caregivers and the care providers of clinics and programs.

The two-week immersion in Guatemala was planned to enhance student learning of occupational justice, first through language, culture and hands-on experiences engaging with local populations, and second through work in clinical settings. For the purpose of this study, focus group sessions were the concluding activity of each day's schedule of events.

\section{Data Collection}

With the University's IRB approval, each participant consented prior to researchers coding the information collected. Students participated in student-led reflections throughout the cultural immersion experience. Student-led reflections occurred each day for 12 days, ranging from 33-78 minutes in length. All reflection discussions were audio-recorded. Reflection discussion prompts included identifying high and low aspects of the day, examining manifestations of discomfort or dissonance referred to in Mezirow's transformative learning theory, and analyzing new and different perspectives. ${ }^{10}$

\section{Analysis}

Audio recordings of the reflection sessions were transcribed by a member of the research team. Transcripts of all focus groups were analyzed by the three authors. Thematic analysis was conducted with each researcher first reading the entire transcript three times, practicing open coding on the last reading. Researchers then compared and contrasted their codes, agreeing on a final code list with 54 operational definitions. Transcripts were then coded according to the final code list and entered into HyperResearch ${ }^{\circledR}$ for further analysis. Thirty-nine descriptive memos were drafted. Data was further reduced and reorganized into 13 analytic memos. Analytic memos were further reduced to form three themes. Frequency counts for each analytic memo were considered in determining patterns that resulted in the final themes. ${ }^{36}$

\section{Trustworthiness}

Student-facilitated reflections each day across 12 days allowed for more authentic responses than if they had been led by the course instructor. This prolonged engagement allowed for trust and rapport to develop among the informants. Triangulation of researchers minimized the personal bias, beliefs, or assumptions about cultural immersion programs of one researcher. The experiences of each researcher included the course instructor, a student researcher who was a Spanish native speaker, and a researcher familiar with the cultural immersion experience and qualitative research. Additionally, triangulation of data sources was provided with 15 informants, which allowed greater depth and breadth of the shared cultural immersion experience. ${ }^{37}$ The triangulation of data sources permitted verification of experiences shared. ${ }^{37}$

\section{RESULTS}

Data analysis yielded three themes: Do, Experience, Understand; Change Factor; and Future Action that represent the student perspective in a cultural immersion experience, as depicted in Figure 1.

Considering the frequency of analytic memos supported the development of the final three themes. Figure 2 indicates the grouping of analytic memos supporting each theme. As illustrated in Figure 2, interaction was most related to the theme of $D$ o, Experience, Understand, emphasizing the importance of engaging with the local community during an immersion experience. The theme of Change Factor included the prevalence of student learning affecting their transformation. Additionally, advocacy was the major concept supporting the theme of Future Action. While quantitative data is typically not included in qualitative research, the researchers utilized frequency counts to discover the impact of shared reflections. 


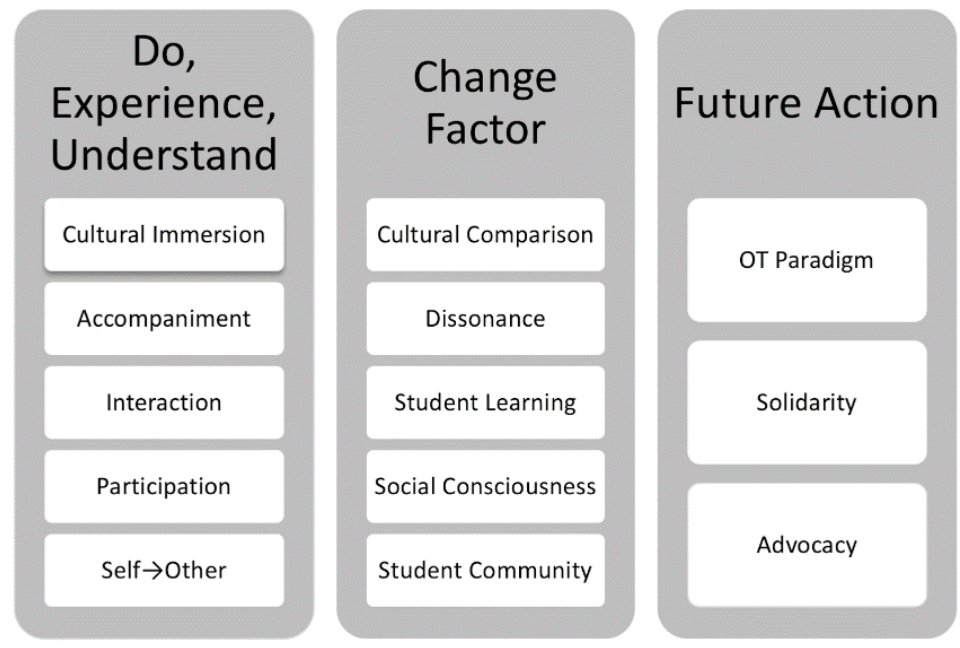

Figure 1. Themes and Subthemes

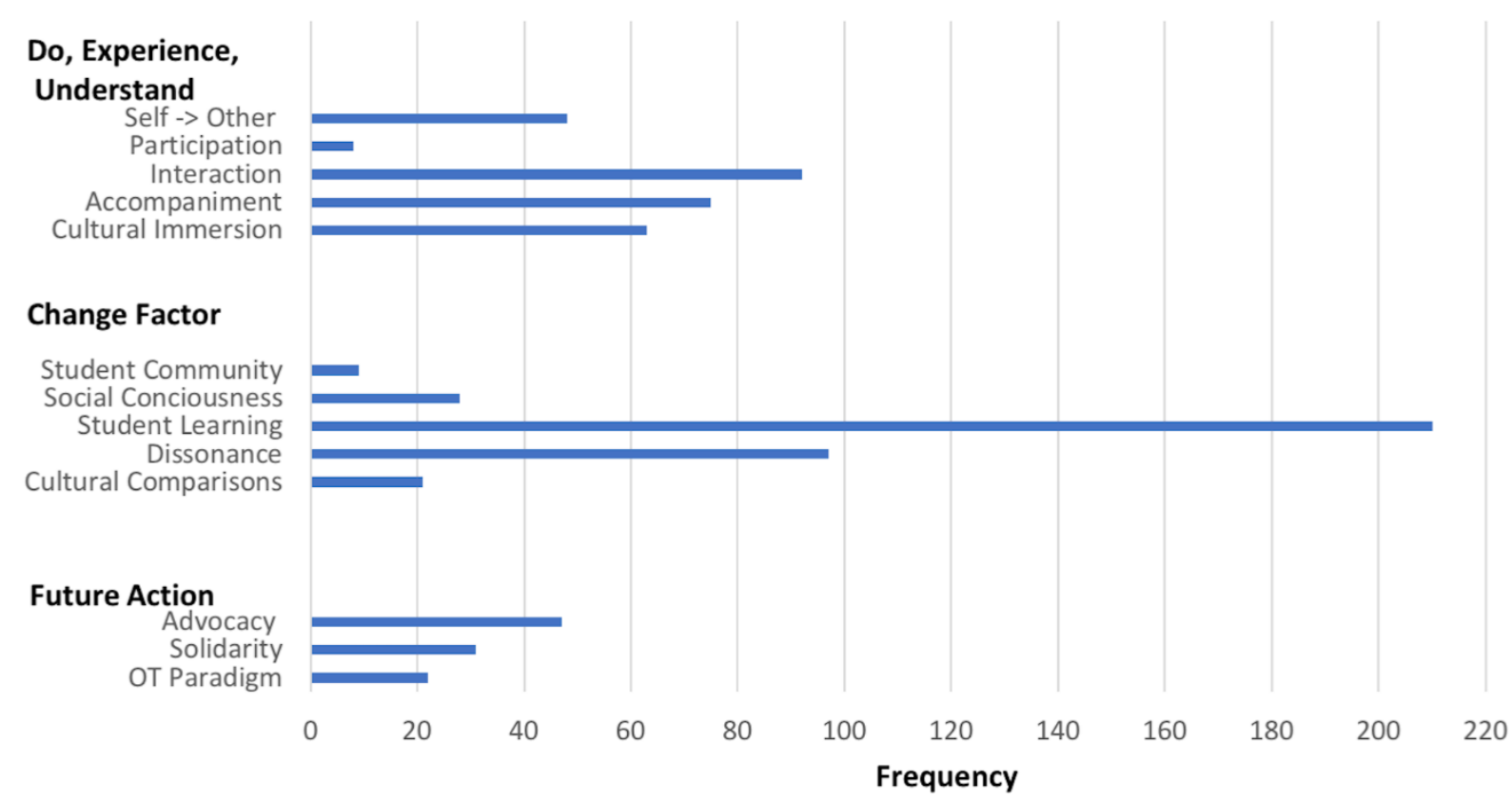

Figure 2: Frequency Counts of Analytic Memos Supporting Themes

The first theme: Do, Experience, Understand captured the informants' realization of fully engaging with others in a culture different from their own, and enhanced their understanding of that culture. Informants perceived greater meaning in the cultural immersion experience than as a bystander. Full engagement was reported as multisensory in nature, while the participants' role was described as accompanying those they served.

Participants described cultural immersion as exposure to other cultures. This exposure led to an awareness of the differences when compared to their own culture. As one participant shared:

One of the biggest things I have learned these past two weeks is my knowledge of the global differences. I feel like all my life I have been in the bubble of the US and could never really know the social justice issues that were intertwined. I would never experience extreme poverty in the United States and with issues with immigration and especially living in Ohio the entire time, just being able to experience people's stories and the 
people I came in contact with really helped me open my eyes with all the differences that we don't see in the United States. (Participant 6)

A fully immersive experience allowed students to form deeper relationships with members of the local community. This connection allowed for a greater understanding of the culture, promoting solidarity and increased empathy.

Students reported that linguistic challenges affected the level of interaction. As one student described, linguistic limitations were a barrier and a source of discomfort:

...in our host families there are times when we just can't get our point across, and can't understand each other. And there are also times when we just stare at each other. It's kind of embarrassing sometimes because we don't know what to say. (Participant 9)

Yet experiences were shared when linguistics challenges were overcome with non-verbal communication. As one participant shared, connections were built through non-verbal communication:

I was just able to communicate with the old ladies, just be looking at them in the eye and laughing with them,

it was just a time when I could overcome language barriers or just doing the dancing with them. (Participant 3 )

Establishing deeper connection with members of the local culture led to the development of an altruistic rather than individualistic mindset. Students reflected on how they imagined that cultural immersion experience would influence their practice as a therapist, as indicated by this student's reflection:

I think with me going into practice, we should be willing to do whatever it takes to get our clients, and be willing to go outside of clinic time or hours if it's for the best of the client. (Participant 15)

When comparing the experiential nature of the immersive learning experience with classroom instruction pertaining to the challenges of those less fortunate and in different cultures, one student stated:

...just seeing it in real life just makes it more real. I remember the first time we came and we were walking on the stone streets, and when we watched the video of people in wheelchairs and how they get around, and then seeing it in real life, it was like wow how do they really do this? (Participant 1)

The cultural immersion experience supported the theme, Do, Experience, Understand, as students shared how their interactions and participation in a culture unlike their own led to a greater awareness of culture and its impact on client-centered practice.

The second theme, Change Factor, centered on moments of internal conflict, prompting participants to enter into a discernment process. Reflection during the discernment process led to personal change and potential transformation. Participants reported moments ranging from personal discomfort to periods of deep internal conflict. Exposure to a new perspective or idea can increase one's self-awareness of familiar frames of reference. It is the consciousness raising that can lead to change. A participant shared her self-awareness by stating:

I'm not going to lie I tend to avoid having these types of conversations because they make me feel uncomfortable. Like a lot of you said, I still tend to have so many questions, and I don't know how exactly I tend to view it, and I hope I continue to ask and continue to have the courage to have these conversations throughout my time here and kind of just continue to open up new horizons and learn as much as I possibly can through listening and just experiencing. (Participant 10)

Through the safe environment of student-led reflections, participants recognized the need to deal with the dissonance, viewing it as an important aspect of their ongoing work in the development of intercultural competence. The discomfort caused by the removal of the students from all things familiar during an immersion led the student to quickly recognize the high level of dissonance that can occur.

... like I said I'm a planner, so I had this idea of what I thought it would look like, and obviously it's not going to happen every time-so continuing to push myself being comfortable with the uncomfortable. (Participant 10)

An immersion experience can prompt one to question one's assumptions, perspectives and mindsets. The disorientation and questioning can lead to an expansion of mindset and the creation of new frames of reference. A participant shared her description of how the immersion program led to personal transformation. 
I really wanted to come on this trip for my own personal growth. A year ago I would have never thought about leaving the country, this is actually my first time going out of the United States, and I'm so grateful that I did, through this and these last two weeks I have felt a transformation and it has been from going outside of your comfort zone and feeling like you are at a place, and feeling like a minority and getting those stares. (Participant 4)

Immersion in a new culture and its language is experiential learning that fosters critical self-reflection. This critical dialogue can lead to transformation and action. Participants recognized the necessity to process the experience through critical reflection, such as how this student shared her views: "I think it really helped us just reflect and be able to get to where emotions and ideas can be impacted by this experience." (Participant 9) A second participant acknowledged the deep work involved in reflection and how this work is enhanced by reflecting with others.

and when you actually process stuff, it's really nice to hear other people's questions and they noticed things you didn't notice or you didn't realize you have the same questions, and its stuff about like oh I didn't even have that question or I didn't even notice that because it seemed natural to me. And although I am processing through the whole $30,40,50$, minute reflection, my mind is still thinking throughout the whole thing. And I think I talked about this yesterday how you only know how to process it all yourself every day and just being able to remember things more. Like I remember things more of what we did last week because I thought about it more after it had happened, so it's cool. (Participant 8)

During student-led reflections, students grappled with unresolved issues stemming from a place of privilege, and at times dealt with the unsettling realization that they or their place of origin could have intentionally or inadvertently influenced current situations of injustice through actions, decisions, indifference or silence.

Before coming here I was like immigration is so bad, immigration is terrible for the US, other people are taking Americans jobs, and after hearing about the immigration talk I didn't even know about the girl that was shot at the border and that really struck me, and just hearing about Willie and even though he doesn't think Guatemalans should immigrate to American forever, and even though the United States can provide the resources there are so many other options that we can provide for Guatemala so people don't have to risk their lives to come to the United States. So I definitely think my political stances have changed during this experience. (Participant 7)

The cultural immersion supported the theme of change, particularly as students reflected on cultural comparisons, the dissonance that the immersion often caused, and the increased level of social consciousness that developed due to processing of physical discomfort and internal conflict.

The last theme, Future Action, refers to the impact of the student-led reflections on motivation for social change and advocacy upon their return. New perspectives prompted students to express a call for future action through informed decision-making related to consumerism, sustainability, politics, and solidarity with marginalized populations. Shared reflection included future personal choices in light of their own privilege:

Yes, we are very educated, and yes, we have a lot of privilege, but it's not a bad thing that you have it-It's just how you use it. I think that's something that we should not feel like guilty about our privilege, but using it to help others and to inspire others. I think that is something we have to remember to do and something we can definitely take back with us. (Participant 5)

Students reflected on a desire to not only apply their privileges to seek positive changes, but also to consider their immersion experience as they practice in professional settings.

I learned, and it's kind of going off of what they said, but occupational deprivation is something that is very present here, and it looks a lot different than what I thought it was going to look, I thought it was going to look like people just not having anything to do, but it's just like lack of meaningful occupation to say the less, and it's all just really striking and that's something l'm going to bring with me as we start our second course of occupational justice course. (Participant 2)

Students reported realizing the impact of one's everyday decisions on global realities. Most noted was a transformation from a focus on individual needs to the impact of their actions on their local and global community. Through this transformation, participants continued a desire to care about their sense of self, yet they also gained an increased sense of social responsibility. A behavioral outcome of this transformation is practicing informed consumerism, as one participant shared: 
It gave me something to think about was when we were at the woman's cooperative today buying things knowing that when we are going to the market in Chichicastenango the prices might be lower, but like buying at the cooperative we were going to be directly supporting women so kind of wrestling to like hey do we want to pay more for like this cause that I really believe in or do I want to save my money. Like am I going to put my values where my mouth is this time? (Participant 12)

Students' personal development emerged from their desire to continue the awareness and sensitivities developed during the immersion experience in their personal lives and future professional roles.

In addition to the themes, reflection was a key element in the transformative nature of the learning experience. In this investigation, it became obvious that the more the students felt that the group was a safe environment in which to share dreams, doubts, cultural missteps and successful moments, the more that the students began to form bonds with each other and with faculty and community members. The level of comfort and cohesiveness of the group provided for lower anxiety and more opportunities for learning. For example, one participant shared her appreciation for the group dynamics:

It really helped me become intimate with you guys because there was times when we would start crying and share things that you typically would not share. Like I shared political views that you don't really share often, but I did that because it was changed and I was really impacted on this program and experience, and I think it really helped us just reflect and be able to get to where emotions and ideas can be impacted by this experience. (Participant 6)

The students' reflection sessions served as a sympathetic ear when basic needs were not met (hunger, illness, physical discomforts, emotional challenges of missing loved ones back home), but could also function as a springboard to deeper reflection of the social injustices observed and experienced during the immersion.

Students were prompted to reflect on the process of student-led critical dialogue during the immersion experience. Reflecting on critical incidents and insights gained during reflection sessions aided students in realizing how their decisions could contribute to society, as illustrated by the following quote:

We talked a lot about privilege and stuff like that and we did a lot of reflection with that and became aware of that, but I think coming here really made me see that on a completely different level and it was something that was really hard for me, and I felt really guilty at first. It was hard to see all the things that we saw, and not feel guilty but the second week has helped me learn that instead of feeling guilty, we need to use our privilege to empower people and realizing that is something we can do is something that is really special to me. (Participant 7 )

The critical reflection that occurred throughout the international experience was conducted as informal discussions led by the participants themselves. The supportive context of the daily reflections permitted learners to share feelings and thoughts in an authentic manner, yet at the same time, challenged them to reexamine existing perspectives through new lenses.

\section{DISCUSSION}

According to Mezirow, a disorienting dilemma or situation can prompt one to question one's assumptions, perspectives and mindsets. ${ }^{38}$ The dissonance that is caused by the disorientation and questioning can lead to transformative learning, that is, an expansion of mindset and the creation of new frames of reference. By recording and describing in real time the perspectives of students during student-led daily reflection sessions, we gain a deeper level of insights into their experiences of dissonance while participating in an immersion experience. Through the immersion program, students had the experience of being in the minority culture, which led to emotional and physical discomfort and comparisons to their own culture. Having the student-led reflection opportunities allowed students a safe space to process in-depth questions and strong emotions helping to reorganize their perspective. As student perspectives evolved, their worldview changed with a greater awareness of others. ${ }^{7}$

The emerging themes describe the authentic student perspective of the immersion experience. Participants' experience in the immersion program was similar to that described in other studies. Participants' recognition of the shift from being in the majority to the minority was beneficial in developing an awareness of one's perspective and bias. ${ }^{27} \mathrm{~A}$ total immersion in the local culture allowed for greater understanding and identification of cultural factors. ${ }^{27}$ Similar to Humbert, participants were able to engage on an emotional level once achieving a certain level of comfort.

Student reflections throughout the immersion experience deepened their awareness of their own identity, attitudes, and perspectives ${ }^{4,7}$ Additionally, students became aware of their personal views and perspectives and the impact their assumptions 
may have on their future practice, as suggested by studies by both Hammell and Muñoz. This enlightened perspective is a component of the process of developing intercultural competence, according to many authors. $14,15,19,39,40$

Cultural competency begins with self-awareness, and the cultural awareness that Muñoz has cited as key to providing culturally responsive care. ${ }^{15}$ As cultural competence is a lifelong process of continued learning and reflection, one outcome of this study included an increased desire to advocate on the behalf of others. Students projected how their immersion experience impacted their future practice as a healthcare professional. When prompted, participants described their desire to continue developing their intercultural competence. Several scholars have proposed continued development of cultural competency as a necessity for clientcentered care. 14,15,16,19,39,40 Developing intercultural competence will prepare students to work in diverse settings with diverse groups. The immersion experience required a guide to negotiate the cultural differences, which provided a level of sensitivity to better assess the contextual factors affecting occupational performance. ${ }^{31}$ This assessment of contextual factors can redistribute the power imbalance often found in therapist-client relationships. $14,15,20$ The lifelong process of cultural competence requires continual reflection and cultural awareness. Through immersion learning experiences, students experienced the value of reflection and cultural awareness.

\section{Limitations}

There are several limitations that may have affected the outcomes reported here. First, as stated previously, five students began this immersion experience having participated in various types of prior study abroad programs, therefore influencing their expectations for this experience. Second, the sample size of $\mathrm{N}=15$ may limit transferability. Researchers provided enough information to allow the readers to consider the results in light of their own context. Third, the personal experiences and student perspectives described here prompted us to believe that they led to transformative learning, yet we cannot claim causality. Since two of the researchers were present during the reflection focus groups, bias still is possible. Finally, the student perspectives presented here are limited, due to the fact that participants were all female, white and from middle to upper class socio-economic backgrounds.

\section{Implications}

Daily reflections prompted students to initiate the continual process of cultural awareness necessary for building cultural competence by questioning their previously held assumptions and judgements. Student perspectives revealed deep critical reflection, encouraged through the implementation of student-led focus groups, prompting greater authenticity in the level of intimacy in which participants shared thoughts, hopes, fears, challenges, and previously held perspectives. The immersion experience and the opportunity to process the dissonance in a safe environment during group reflection allowed students to explore new perspectives, a foundation for increasing self-awareness and for building intercultural competence.

A strongly integrated curricular immersion program can provide the foundation for the ongoing development of intercultural competence necessary to provide client centered care. ${ }^{20}$ However, curricular integration alone does not guarantee a successfully prepared practitioner to work with diverse populations. Perspective sharing during student-led focus groups revealed the need for a supportive atmosphere of peers and professionals to assist them with interpretations of cultural norms in a new context, as well as with internal conflicts that can ultimately lead to transformative learning experiences.

\section{CONCLUSION}

The demand for client centered practice, along with the increasing diversity of clients across borders challenges occupational therapy preparation programs to produce professionals demonstrating intercultural competence. This study addresses a gap in research literature related to student-led reflection leading to transformative learning and the increase of cultural awareness. Using student-led reflections recorded in real time, participants' perspectives revealed the need to minimize power and privilege when working with clients of less privileged backgrounds, and the need to avoid projecting their own culture onto their future clients. Participants' verbalized descriptions of transformative learning necessary in the development of intercultural competency during an international cultural immersion experience. By participating in a cultural immersion experience integrated into their curricular program, students shared greater self-awareness through deep critical reflection and transformed attitudes which together lay the foundation for further cultural competency development necessary to provide client-centered, culturally responsive care..$^{15} \mathrm{As}$ stated previously, cultural competence is a lifelong practice, and through the practice of reflection during an immersion experience, students developed the skills necessary to continue this process throughout their careers.

\section{ACKNOWLEDGEMENTS}

The authors would like to thank the students for their authentic participation in the study. 


\section{REFERENCES}

1. AOTA salary and workforce survey for 2015. Bethesda, MD: American Occupational Therapy Association; 2015.

2. American Occupational Therapy Association. 2011 Accreditation Council for Occupational Therapy Education (ACOTE®) standards. Amer J Occup Ther. 2012; 66: S6-S74. doi:10.5014/ajot.2012.66S6

3. American Occupational Therapy Association. 2018 Accreditation Council for Occupational Therapy Education (ACOTE ${ }^{\circledR}$ ) Standards and Interpretive Guide (effective July 31, 2020). Amer J Occup Ther. 2018;72. 7212410005p17212410005p83. doi:10.5014/ajot.2018.72S217

4. Murden R, Norman A, Ross J, Sturdivant E, Kedia M, Shah S. Occupational therapy students' perceptions of their cultural awareness and competency. Occup Ther Int. 2008;15(3):191-203. doi.org/10.1002/oti.253

5. Kale S, Hong CS. An investigation of therapy student's perception of cultural awareness. Int J Ther Rehabil. 2007;14(5): 210-214. doi.org/10.12968/ijtr.2007.14.5.23538

6. Crowe T, Sanchez, V, Weber, Murtagh, A. The influence of a Mexican cultural immersion experience on personal and professional healthcare practices. Occup Ther Int. 2016;23(4):318-327. [PMID: 27250734]

7. Ekelman B, Dal Bello-Haas V, Bazyk, J, Bazyk, S. Developing cultural competence in occupational therapy and physical therapy education: a field immersion approach. J Allied Health. 2003;32(2): 131-137. https://files.eric.ed.gov/fulltext/EJ868239.pdf. Accessed January 23, 2019. [PMID: 12801027]

8. Goodard T, Gibble N. A service learning relationship fostering cultural competency: the cultural immersion of occupational therapy students and reflective practice. In: Shortland-Jones B. ed. Enhancing student learning: Evaluations and Assessment Conference. Bentley, Western Australia: Curtin University of Technology; 2006;7-12.

9. Cipriani J. Integration of international service learning in developing countries within occupational therapy education: Process and implications. Occup Ther Health Care. 2017;31(1):61-71. [PMID: 27805838]

10. Mezirow J. Transformative dimensions of adult learning. San Francisco: Jossey-Bass; 1991.

11. Deardorff $D$. Identification and assessment of intercultural competence as a student outcome of internationalization. J Stud Int Educ. 2006;10(3):241-266.

12. Fantini A. Assessing intercultural competence: Issues and tools. In Deardorff DK ed. The SAGE Handbook of Intercultural Competence. Thousand Oaks, CA: Sage Publishing; 2009;456-477.

13. Sinecrope $\mathrm{C}$, Norris $\mathrm{J}$, Watanabe $\mathrm{Y}$. Understanding and assessing intercultural competence: a summary of theory, research and practice. Second Lang Stud. 2007;26(1):1-58.

14. Black RM, Wells SA. Culture and occupation: A model of empowerment in occupational therapy. Bethesda, MD: AOTA Press; 2007.

15. Muñoz JP. Culturally responsive caring in occupational therapy. Occup Ther Int 2007; 14(4): 256-280. doi.org/10.1002/oti [PMID: 17966110]

16. Campinha-Bacote J. The Journey continues: The Process of cultural competence in the delivery of healthcare services. Cincinnati, OH: Transcultural C.A.R.E. Associates; 2007.

17. Papadopoulos I. The Papadopoulos, Tilki and Talor model of developing cultural competence. In Papadopoulos I ed. Transcultural Health and Social Care: Development of Culturally Competent Practitioners. Churchill Livingstone Elsevier, Edinburgh; 2006.

18. Betancourt JR, Green AR, Carrilo JE, Ananeh-Firempong II O. Defining cultural competence: A Practical framework for addressing racial/ethnic disparities in health and health care. Pub Health Rep 2003; 118(4): 293. Retrieved from: http://search.ebscohost.com/login.aspx?direct=true\&db=edsjsr\&AN=edsjs. $4598855 \&$ site=eds-live\&scope=site

19. Balcazar FE, Suarez-Balcazar Y, Taylor-Ritzler T. Cultural competence: Development of a conceptural framework. Disability and Rehabilitation 2009; 31(14): 1153-1160. doi.org/10.1080/09638280902773752

20. Grady S, Brungardt K, Doll J. The Impact of classroom instruction on cultural awareness and sensitivity in occupational therapy students. J Occup Ther Educ 2018; 2(2). doi.org/10.26681/jote.2018.020201

21. Dewey, J. Experience and education. New York: McMillian; 1938.

22. Kolb, D. Experiential learning: Experience as the source of learning and development. Engelwood Cliffs, NJ: Prentice Hall; 1984.

23. Cranton, P. Understanding and promoting transformative learning: A Guide to theory and practice. San Francisco: Jossey-Bass; 2016.

24. Taylor, EW. Critical reflection and transformative learning: A Critical review. PAACE J Lifelong Learning 2017; 26:7795. Retrieved from https://www.iup.edu/ace/paace/v26-2017/

25. Savicki V, Price MV. Guiding reflection on cultural experience: Before, during and after study abroad. In Parquareli SL, Cole PA, Tyson M. eds. Passport to change: Designing academically sound, culturally relevant, short-term faculty-led study abroad programs. Sterling, VA: Stylus; 2017; 28-37. 
26. Paige R M. Interventionist models for study abroad. In Bennett J M. ed. SAGE encyclopedia of intercultural competence. Thousand Oaks, CA: Sage; 2015; 563-68.

27. Mu K, Coppard BM, Bracciano A, Doll J, Matthews A. Fostering cultural competency, clinical reasoning, and leadership through international outreach. Occup Ther Health Care 2010; 24(1): 74-85. Retrieved from

http://libproxy.xu.edu:2048/login?url=http://search.ebscohost.com/login.aspx?direct=true\&d=swh\&AN=79544\&site=eds -live\&scope=site [PMID: 23898876]

28. Darawsheh W, Chard $\mathrm{G}$. The challenge of cultural competency in the multicultural 21 st century: a conceptual model to guide occupational therapy practice. Open J Occup Ther. 2015;3(2): 1-22. doi.org/10.15453/2168-6408.1147

29. Humbert TK, Burket A, Deveney R, Kennedy K. Occupational therapy students' perspectives regarding international cross-cultural experiences. Aust Occup Ther J 2012:59(5): 225-234. doi.org/10.1111/j.1440-1630.2011.00987.x [PMID: 22690773]

30. Sonn I, Vermeulen N. Occupational therapy students' experiences and perceptions of culture during fieldwork education. South African J Occup Ther 2018;48(1): 34-39. doi.org/10.17159/2310-3833/2017/vol48n1a7 [PMID: 18496787]

31. Simonelis J, Njelesani J, Novak L, Kuzma C, Cameron D. (n.d.). International fieldwork placements and occupational therapy: Lived experiences of the major stakeholders. Aust Occup Ther J n.d. 58(3): 370-377. doi.org/10.1111/j.14401630.2011.00942.x [PMID: 21957922]

32. Vaismoradi $\mathrm{M}$, Turenen $\mathrm{H}$, Bondas $\mathrm{T}$. Content analysis and thematic analysis: implications for conducting a qualitative descriptive study. Nurs Health Sci. 2013;15(3): 398-405. Doi.org/10.1111/nhs.12048 [PMID: 23480423]

33. Magilvy JK, Thomas E. A first qualitative project: qualitative description design for novice researchers. J Spec Pediatr Nurs. 2009; 14(4):298-300.

34. Bureau UC. Decennial Census Official Publications. Decennial Census of Population and Housing. https://www.census.gov/programs-surveys/decennial-census/decade/decennial-publications.html. Published 2010. Accessed February 21, 2019.

35. Townsend, E. Muriel Driver Lecture: Occupational therapy's social vision. (1993). 1993 Muriel Driver Lecture: Occupational therapy's social vision. Can J Occup Ther 1993; 60(4): 174-184. doi.org/10.1177/000841749306000403 [PMID: 10129020]

36. Maxwell J. A. Using numbers in qualitative research. Qual Inquiry. 2010; 16(6): 475-482. doi.org/10.1177\%2F1077800410364740

37. Krefting L. Rigor in qualitative research: the assessment of trustworthiness. Amer J Occup Ther. 1991; 45(3): 214-222. doi.org/10.5014/ajot.45.3.214 [PMID: 2031523]

38. Mezirow J Learning to think like an adult. In Mezirow J \& Associates. eds. Learning as transformation: Critical perspectives on a theory in progress. San Francisco: Jossey-Bass; 2000;3-33.

39. Hammell KR. Client-centered practice in occupational therapy: critical reflections. Scand J Occup Ther. 2013;20(3):174-81. doi.org/10.3109/11038128.2012.752032 PMID: 20170413

40. Awaad T. Cultural competency and occupational therapy: a review of literature. Br J of Occup T 2003; 66(8):356-362. doi.org/10.1177/030802260306600804 